\title{
The commitment: A determinant basic mental skill in student's performance in Physical Education and Sport
}

\author{
Eloirdi A. ${ }^{1 \mathrm{ABCDE}^{*}}$, Mammad K. ${ }^{1 \mathrm{D}}$, Arfaoui A. ${ }^{2 \mathrm{C}}$, Ahami A. ${ }^{\mathrm{ABCDE}}$ \\ ${ }^{1}$ Team Clinical Neuroscience, Cognitive and Health, Laboratory of Biology and Health, Faculty of Science, Ibn Tofail \\ University, Morocco \\ ${ }^{2}$ Executive Training Royal Institute of Youth and Sports, Morocco
}

Authors' Contribution: A - Study design; B - Data collection; C - Statistical analysis; D - Manuscript Preparation; E - Funds Collection.

\begin{abstract}
Purpose: $\quad$ Mental skills and motivation are key factors in learning and performance. This study aims to model their influence on performance in physical education and sport among Moroccan high school students.

Material: $\quad$ A sample of 202 high school students including 100 boys and 102 girls participated in this study. In order to assess mental skills, we used the Ottawa Mental Skills Assessment Tool (OMSAT-3) test and to assess different forms of motivation, we used the Sport Motivation Scale (SMS-28). To evaluate the performance in physical education and sport, we chose an individual sport that is the high jump.

Results: $\quad$ The multiple linear regression has as a dependent variable performance in physical education and sport and as explanatory variables mental skills and motivational forms retained only commitment.

Conclusions: The commitment, as basic mental skill, is determinant in student's performance in physical education and sport.

Keywords: mental skills, motivation, commitment, performance, physical education, sport.
\end{abstract}

\section{Introduction}

Research on the issue of motor learning and motor performance is still progressing. Currently, work in the fields of psychology and neuroscience has a significant interest in understanding learning processes and neurocognitive factors that can influence motor performance. In addition to physical and technical qualities, motor practice requires mental qualities [1]. The latter are determining in the motor performance [2]. Mental skills are a set of processes that allow us to control and direct the thoughts, feelings, or emotions that are essential for learning and performance [3]. they are classified in three families: Basic skills, psychosomatic skills, Cognitive skills. Basic skills contain goal setting, commitment, self-confidence. Psychosomatic skills manifested in: stress reactions, control of fear, relaxation, and activation. Cognitive skills contain concentration, distraction control, mental imagery, mental practice, planning [4].

Many research has shown the role of motivation in the success of all learning [5,6]. Motivation, by definition, is "a process of action directed toward a goal" [7]. It is also "a hypothetical construct used to describe the internal and / or external forces that produce the trigger, the direction, the intensity and persistence of behaviour" [8]. According to the theory of self-determination [9], we distinguish: Intrinsic motivation, Extrinsic motivation and Amotivation. Intrinsic motivation devise to four categories: intrinsic motivation to knowledge, intrinsic motivation to achievement, motivation intrinsic to stimulation. While the extrinsic motivation devise to three categories: extrinsic motivation with identified regulation, extrinsic motivation with introjected regulation, and

(c) Eloirdi A., Mammad K., Arfaoui A., Ahami A., 2018

doi:10.15561/18189172.2018.0504 extrinsic motivation with external regulation.

Hypothesis: Mental skills and forms of motivation, including basic mental skills and forms of intrinsic motivation, significantly explain the variation of performance in physical education and sports.

Purpose: The objective of the current study is to model the influence of mental skills and motivation on performance in physical education and sport among Moroccan high school students.

\section{Materials and methods}

Participants: The study was carried out 2 months of year 2015 in Moroccan high school situated in Sidi Slimane province that belongs to Rabat-Salé-Kenitra region in the North West of Morocco. The studied classes were chosen randomly. We conducted our study with a sample of 202 high school students, including 100 boys (mean age $=17 \pm 1.2$ years) and 102 girls (mean age $=$ $16 \pm 1.3$ years). They all have a good physical ability that allows them to practice sports and they represent all the academic levels of the high school and all the streams.

Measure of mental skills: To assess mental skills. We used the version 3 of the Ottawa Mental Skills Assessment Tool (OMSAT-3) with 48 Items [4]. It evaluates twelve mental skills ranked by the authors [4] as follows: Fundamental skills (goal setting, selfconfidence, commitment), psychosomatic skills (stress reactions, fear control, relaxation and activation) and cognitive skills (concentration, distractions control, imagery, mental practice, competition planning). The scores of the 12 scales correspond to the means of selfevaluation of 4 affirmations, in a Likert scale of 7 choices (from totally disagree to completely agree). The test has good psychometric properties [4].

Measure of motivation: To assess student motivation 
in physical education and sport. We used the Sport Motivation Scale (SMS-28) [10]. This tool consists of 28 items divided into seven subscales to measure different forms of motivation. For each item, the student positions himself on a seven-point Likert scale according to his degree of correspondence with the different statements. For example, it surrounds the number 1 if the affirmation "does not correspond to it at all" and it surrounds the number 7 if it "corresponds to it". The scale has good psychometric properties [10].

Measure of performance in physical education and sport (PES): We chose an individual sport that is the high jump to evaluate the performance. To do this, the subjects underwent twelve learning sessions during which the student technically learns how to perform the jump. We evaluated the process (how the jump was made) and the product (the height in $\mathrm{cm}$ ). In order to evaluate the process, we established four criteria: The run (trampling or not): 1.75 points; The call (correct or incorrect): 1.75 points; The crossing (dodge or not): 1.75 points and The fall (on the shoulders or not): 1.75 points. The product was scored on 7 points according to a scale drawn from the pedagogical guidelines of physical education and sport .

\section{Statistical analysis}

We used Pearson's correlation coefficient to assess the association between mental skills, forms of motivation and performance in physical education and sport. To model the link between performance in physical education and sport, mental skills and motivation, we used a multiple linear regression.

\section{Results}

Modelling the influence of mental skills and forms of motivation on performance in physical education and sport

Firstly, we applied correlation tests on the one hand, between mental skills and performance in physical education and sport, and on the other hand, between performance in physical education and sport and the forms of motivation, the results are presented in the tables below.

Correlational analysis showed that performance in physical education and sport as a significantly positive association with the following mental skills: goal setting, commitment, relaxation, activation, mental imagery, mental practice, and planning and with extrinsic motivation with external regulation (table1,2).

Subsequently, we applied multiple linear regression to look for a model that could possibly combine these variables. However, the multiple linear regression (stepwise method) having as dependent variable the performance in physical education and sport and as explanatory variables the mental skills and the forms of motivation retained only the commitment. In fact, the standardized coefficient of the latter, which is 0.26 , was found to be statistically significant $(\mathrm{t}=3.89, \mathrm{p}<0.001)$

2 Pedagogical orientations and teaching program of the physical education and sport in the qualifying secondary cycle. 2007 whereas those of other mental skills and forms of motivation are not (Table 3 ).

Therefore, the model of linear regression would be:

$$
\mathrm{P}(\mathrm{PES})=0.29 \mathrm{COM}+10.71
$$

The model is statistically good and expresses the data correctly $(\mathrm{F}=15.16, \mathrm{p}<0.001)$.

\section{Discussion}

The objective of this study was to model the influence of mental skills and motivation on performance in physical education and sport among Moroccan high school students.

The results showed that the effect of commitment is dominant over that of other mental skills and motivation. Indeed, commitment is a basic mental skill related to the determination, perseverance and intensity of the work the subject devotes to accomplishing his goals [11]. The notion of school commitment refers to students' investment in school $[12,13]$. It comprises three dimensions: behavioral, emotional and cognitive $[14,15]$. With respect to the behavioral dimension, this is the way in which the student interacts in the school environment [16]. This dimension is expressed in three areas: disciplinary, school and extracurricular [14]. The disciplinary field concerns the attendance of the student, the school dominion concerns learning and school tasks and extracurricular field refers to the participation of the student in the activities of the school environment. As for the affective dimension of commitment, it is the feeling that the student feels in the school [14], this dimension concerns the usefulness of the subjects, it's mean, the student's feeling towards each subject [17], and the feeling of belonging to the school [18]. Concerning the cognitive dimension of commitment, two aspects can be distinguished: cognitive investment in learning and self-regulation of learning [16]. The first involves the willingness and effort that the student provides during school tasks [14], and concerns several areas such as learning goals, sense of competence and academic aspirations. The second aspect refers to the metacognitive strategies used in the organization of work [14].

Otherwise, many studies have shown, in general and not only in physical education and sports, that commitment explains success or failure in school [19, $20,21,22,23]$. That is, if the student has a high level of commitment, his results will be positive. On the contrary, if he shows a lower level of commitment, remaining passive in front of the school tasks, his performance will be weak and will tend to fail school. Even more serious, student disengagement from school may lead to dropping out of school $[24,25,26]$. In addition, the commitment would positively influence student performance through the mastery goal, which many studies have shown to be involved in the choice of challenging tasks, strong perseverance, the use of deep and appropriate learning strategies [27, 28, 29, 30, 31]. 


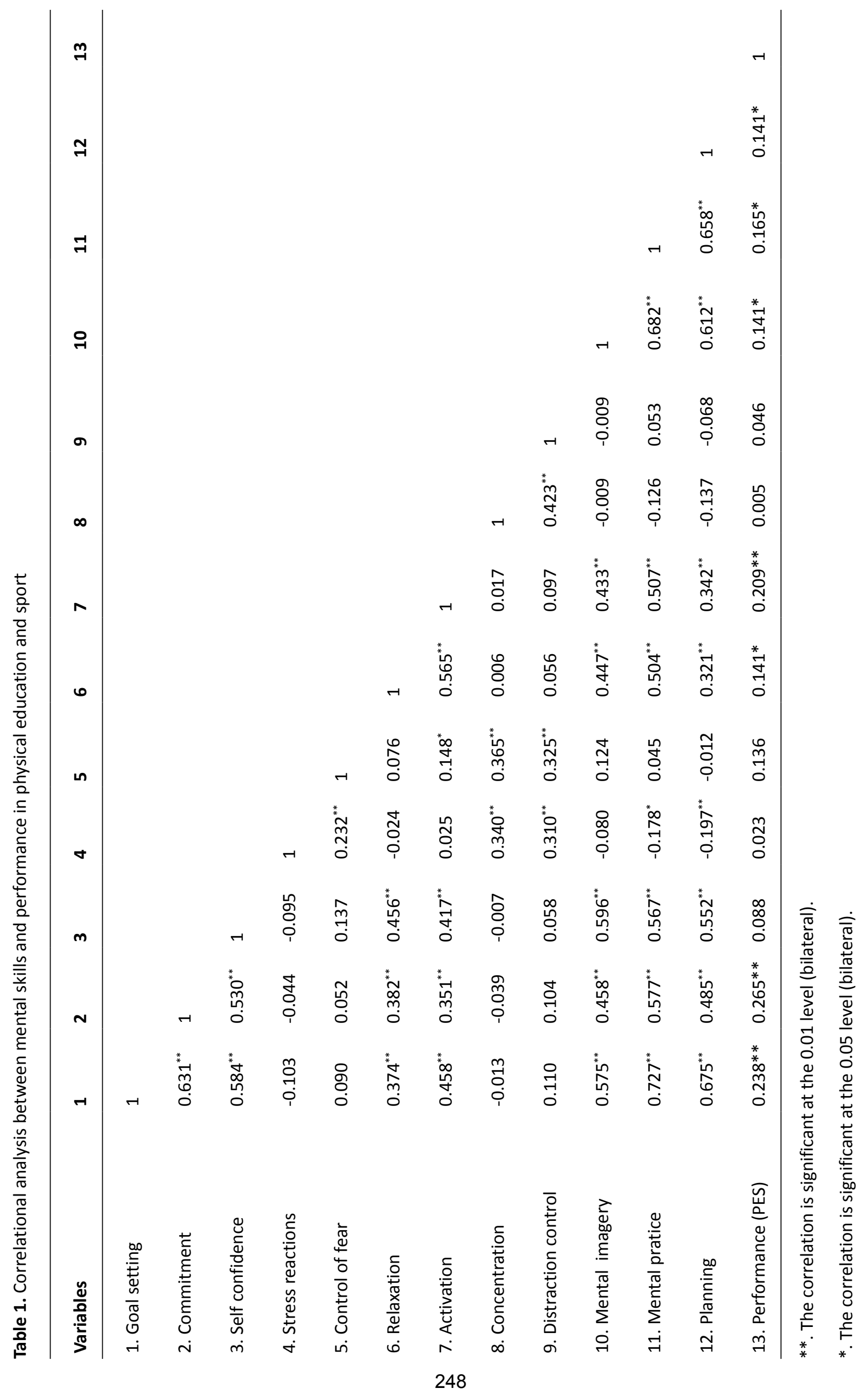


Table 2. Correlational analysis between performance in physical education and sport and motivation forms.

\begin{tabular}{|c|c|c|c|c|c|c|c|c|}
\hline Variables & 1 & 2 & 3 & 4 & 5 & 6 & 7 & 8 \\
\hline 1. $P(P E S)$ & 1 & & & & & & & \\
\hline 2.MIK & 0.032 & 1 & & & & & & \\
\hline 3.MIA & 0.077 & $0.662^{* *}$ & 1 & & & & & \\
\hline 4.MIS & 0.106 & $0.445^{* *}$ & $0.463^{* *}$ & 1 & & & & \\
\hline 5.EMId & 0.077 & $0.384^{* *}$ & $0.357^{* *}$ & $0.287^{* *}$ & 1 & & & \\
\hline 6.EMIn & 0.026 & $0.421^{* *}$ & $0.394^{* *}$ & $0.370^{* *}$ & $0.406^{* *}$ & 1 & & \\
\hline 7.EMER & $0.214^{* *}$ & $0.197^{* *}$ & $0.228^{* *}$ & $0.222^{* *}$ & $0.370^{* *}$ & $0.282^{* *}$ & 1 & \\
\hline 8. AM & -0.084 & $-0.246^{* *}$ & $-0.300^{* *}$ & $-0.219^{* *}$ & $-0.250^{* *}$ & $-0.382^{* *}$ & -0.106 & 1 \\
\hline
\end{tabular}

NOTE: **. The correlation is significant at the 0.01 level (bilateral); *. The correlation is significant at the 0.05 level (bilateral).

P(PES): Performance in Physical Education and Sport; MIK: Motivation intrinsic to knowledge; MIA: Motivation intrinsic to accomplishment; MIS: Motivation intrinsic to stimulation EMId: Extrinsic Motivation with Identified regulation; EMIn: Extrinsic Motivation with Introjected regulation; EMER: Extrinsic motivation with external regulation; AM: Amotivation

Table 3. Standardized coefficients of mental skills and forms of motivation and their Meanings

\begin{tabular}{llll}
\hline Variables & Bêta & $\mathbf{t}$ & Sig \\
\hline MIK & -0.079 & -1.070 & 0.286 \\
MIA & -0.009 & -0.129 & 0.897 \\
MIC & 0.036 & 0.505 & 0.614 \\
EMId & -0.019 & -0.261 & 0.795 \\
EMIn & -0.153 & -1.930 & 0.055 \\
EMRE & 0.137 & 1.883 & 0.061 \\
AM & -0.009 & -0.121 & 0.903 \\
GS & 0.118 & 1.342 & 0.181 \\
COM & 0.26 & 3.89 & $<0.001$ \\
SC & -0.074 & -0.919 & 0.359 \\
SR & 0.035 & 0.507 & 0.613 \\
FC & 1.813 & 0.071 \\
REL & 0.123 & 0.634 & 0.527 \\
ACT & 0.047 & 1.828 & 0.069 \\
CON & 0.132 & 0.228 & 0.820 \\
DC & 0.016 & 0.268 & 0.789 \\
MI & 0.018 & 0.317 & 0.751 \\
MP & 0.024 & 0.219 & 0.827 \\
POC & 0.018 & 0.205 & 0.838 \\
\hline
\end{tabular}

NOTE : MIK: Motivation intrinsic to knowledge; MIA: Motivation intrinsic to accomplishment; MIS: Motivation intrinsic to stimulation; EMId: Extrinsic motivation with identified regulation; EMIn: Extrinsic motivation with introjected regulation; EMER: Extrinsic motivation with external regulation; AM: Amotivation.GS: Goal setting; COM: Commitment; SC: Self-confidence; SR: Stress reactions; FC: Fear Control; REL: Relaxation; ACT: Activation; CON: Concentration; DC: Distraction Control; MI: Mental Imagery; MP: Mental practice; POC: Planning of competitions.

\section{Conclusion}

At the end of this study, it emerges that commitment, as basic mental skill, is determinant in student's performance in physical education and sport. For this, physical education and sports teachers need to establish a climate that encourages student engagement in its different behavioral, emotional and cognitive dimensions.

\section{Conflict of interest}

The authors declare that there is no conflict of interest. 


\section{References}

1. Vallerand RJ, Losier GF. An integrative analysis of intrinsic and extrinsic motivation in sport. Journal of Applied Sport Psychology, 1999;11:142-169.

2. Fournier F. Evaluation des ressources psychologiques des athlètes de haut niveau. [Evaluation of psychological resources of high-level athletes.]. Paris: Laboratoire de Psychologie et d'Ergonomie du Sport- INSEP; 2006. (In French)

3. Smith M. Développement des aptitudes mentales pour les athlètes de haut niveau. [Mental Skills Development for High Performance Athletes]. Science du Sport, 1993; 13: 1-12. (In French)

4. Durand Bush N, Salmela JH, Green-Demers I. The Ottawa Mental Skills Assessment Tool (OMSAT -3). The Sport Psychologist, 2001; 15: 1 -19.

5. Organisation for Economic Co-operation and Development. Comprendre le cerveau: naissance d'une science de l'apprentissage. [Understanding the brain: birth of a science of learning].Centre pour la recherche et l'innovation dans l'enseignement (CERI); 2007. (In French)

6. Pintrich PR. A motivational science perspective on the role of student motivation in learning and teaching contexts. Journal of Educational Psychology, 2003; 95(4): 667-686.

7. Pintrich PR, Schunk H. Motivation in education. Theory, research, and applications. New Jersey: Merill Prentice Hall; 2002.

8. Vallerand, RJ, Thill EE. Introduction au concept de motivation [Introduction to motivation concept]. In: Vallerand RJ , Thill EE (Eds.), Introduction à la psychologie de la motivation. [Introduction to the psychology of motivation]. Laval: Editions études vivantes - Vigot; 1993. P. 3-39. (In French)

9. Ryan RM, Deci EL. Intrinsic and extrinsic motivations: classic definitions and new directions. Contemporary Educational Psychology, 2000; 25: 54-67.

10. Brière NM, Vallerand RJ, Blais MR, Pelletier LG. Développement et Validation d'une Mesure de Motivation Intrinsèque, Extrinsèque et d'Amotivation en Contexte Sportif: L'Échelle de Motivation dans les Sports (ÉMS). [Development and Validation of a Measure of Intrinsic, Extrinsic Motivation and Amotivation in Sports Context: The Scale of Motivation in Sports]. International Journal of Sport Psychology, 1995; 26: 465-489. (In French)

11. Orlick T. The psychology of personal excellence. Contemporary Thought on performance Enhancement, 1992; 1: 109-122.

12.Mahoney JL. School extracurricular activity participation as a moderator in the development of antisocial patterns. Child development, 2000; 71(2): 502-516.

13.McNeal RB. Are students being pulled out of high school? The effect of adolescent employment on dropping out. Sociology of Education, 2003; 70(3): 206-220.

14.Fredricks JA, Blumenfeld PC, Paris AH. School engagement: Potential of the concept, state of the evidence. Review of Educational Research, 2004; 74(1): 59-109.

15.Furlong MJ, Whipple AD, Jean GS, Simental J, Soliz A, Punthuna S. Multiple contexts of school engagement: moving toward a unifying framework for educational research and practice. California School Psychologist, 2003; 8: 99-113.
16.Jimerson SR, Campos E, Greif J.L. Toward an understanding of definitions and measures of school engagement and related terms. California School Psychologist, 2003; 8: 7-27.

17.Eccles J, Wigfield A, Harold RD, Blumenfeld P. Age and gender differences in children's self- and task perceptions during elementary school. Child Development, 1993; 64(3): 830-847.

18.Janosz M, LeBlanc M. Pour une vision intégrative des facteurs reliés à l'abandon scolaire. [For an integrative view of the factors related to school dropout]. Revue canadienne de psycho-éducation, 1996; 25(1): 61-88. (In French)

19.Connell JP, Wellborn JG. Competence, autonomy and relatedness: A motivational analysis of self-system processes. In: Gunnar MR, Sroufe LA (Éds), Self processes in development: Minesota Symposium on Child Psychology. Hillsdale NJ: Erlbaum; 1991;23: 43-77.

20.Deci EL, Hodges R, Pierson L, Tomassone J. Autonomy and competence as motivational factors in students with learning disabilities and emotional handicaps. Journal of Learning Disabilities, 1992; 25(7): 458-469.

21.Ryan RM, Stiller JD, Linch JB. Representations of relationships to teachers, parents, and friends as predictors of academic motivation and self-esteem. Journal of Early Adolescence, 1994; 14(2): 226-249.

22.Skinner EA, Belmont MJ. Motivation in the classroom: Reciprocal effect of teacher behavior and student engagement across school year. Journal of Educational Psychology, 1993; 85(4): 571-581.

23. Valas H, Sovik N. Variables affecting student's intrinsic motivation for school mathematics: Two empirical studies based on Deci and Ryan's theory on motivation. Learning and Instruction, 1994; 3:281-298.

24.Finn JD. Withdrawing from school. Review of Educational Research, 1989; 59(2): 117-142.

25.Finn JD, Rock DA. Academic success among students at risk for school failure. Journal of Applied Psychology, 1997; 82(2): 221-234.

26.Rumberger RW, Ghatak R, Poulous G, Ritter PL, Dornbush SM. Family influence on dropout behavior in one California high school. Sociology of Education, 1990; 63: 283-299.

27.Bouffard T, Boisvert J, Vezeau C, Larouche C. The impact of goal orientation on self regulation and performance among college students. British. Journal of Educational Psychology, 1995; 65: 317-329.

28.Dweck CS. Self-Theories and Goals: Their Role in Motivation, Personality, and Development. Philadelphia: Taylor \& Francis; 1999.

29.Riveiro JMS, Cabanach RG, Arias AV. Multiple-goal pursuit and its relation to cognitive, self-regulatory, and motivational strategies. British Journal of Educational Psychology, 2001; 71 (4): 561-573.

30.Smith M, Duda J, Allen J, Hall H. Contemporary measures of approach and avoi dance goal orientations: Similarities and differences. British Journal of Educational Psychology, 2002; 72(2): 155-190.

31.Harackiewicz JM, Barron KE, Pintrich PR, Elliot AJ, Thrash TM. Revision of achievement goal theory: Necessary and illuminating. Journal of Educational Psychology, 2002; 94(3): 638-645. 
Information about the authors:

Eloirdi A. (Corresponding author); http://orcid.org/0000-0003-1061-7787; eloirdineuro@gmail.com; Team Clinical Neuroscience, Cognitive and Health, Laboratory of Biology and Health, Faculty of Science, IbnTofail University; IbnTofail University, BP. 133, Kenitra, Morocco.

Mammad K.; http://orcid.org/0000-0003-2290-6631; khaoula.mammad@gmail.com; Team Clinical Neuroscience, Cognitive and Health, Laboratory of Biology and Health, Faculty of Science, IbnTofail University; IbnTofail University, BP. 133, Kenitra, Morocco.

Arfaoui A.; http://orcid.org/0000-0002-5705-2536; Amine_arfaoui@yahoo.fr; Executive Training Royal Institute of Youth and Sports; KM 12 Route de Meknes, Salé, Morocco.

Ahami A. http://orcid.org/0000-0002-9340-7920; Ahami_40@yahoo.fr; Team Clinical Neuroscience, Cognitive and Health, Laboratory of Biology and Health, Faculty of Science, IbnTofail University; IbnTofail University, BP. 133, Kenitra, Morocco.

Cite this article as: Eloirdi A, Mammad K, Arfaoui A, Ahami A. The commitment: A determinant basic mental skill in student's performance in Physical Education and Sport. Pedagogics, psychology, medical-biological problems of physical training and sports, 2018;22(5):246-251. doi:10.15561/18189172.2018.0504

The electronic version of this article is the complete one and can be found online at: http://www.sportpedagogy.org.ua/index.php/PPS/issue/archive

This is an Open Access article distributed under the terms of the Creative Commons Attribution License, which permits unrestricted use, distribution, and reproduction in any medium, provided the original work is properly cited (http://creativecommons.org/licenses/by/4.0/deed.en).

Received: 18.08 .2018

Accepted: 10.09.2018; Published: 30.09.2018 